\title{
Genetic variation in ERCC1 and XPF genes and breast cancer risk
}

\author{
X.H. Pei ${ }^{1,4}$, Z. Yang', X.Q. $\mathbf{L v}^{3,4}$ and H.X. $\mathbf{L i}^{3,4}$ \\ ${ }^{1}$ Department of Breast Surgery, \\ The First Affiliated Hospital of Zhengzhou University, Zhengzhou, China \\ ${ }^{2}$ Department of Gastrointestinal Surgery, \\ The First Affiliated Hospital of Zhengzhou University, Zhengzhou, China \\ ${ }^{3}$ Department of Pathology, \\ The First Affiliated Hospital of Zhengzhou University, Zhengzhou, China \\ ${ }^{4}$ Department of Pathology, \\ Basic Medical College of Zhengzhou University, Zhengzhou, China \\ Corresponding author: H.X. Li \\ E-mail: xhpei99@126.com
}

Genet. Mol. Res. 13 (1): 2259-2267 (2014)

Received March 13, 2013

Accepted January 13, 2014

Published March 31, 2014

DOI http://dx.doi.org/10.4238/2014.March.31.6

\begin{abstract}
Breast cancer is one of the most frequently diagnosed cancer in women worldwide, and we conducted a case-control study by genotyping seven potentially functional SNPs, three in ERCC1 and four in XPF, in a Chinese population of 417 breast cancer cases and 417 cancer-free controls. Three SNPs in ERCC1 and four SNPs in XPF were genotyped by using the Taqman Universal PCR Master Mix in the GeneAmp ${ }^{\circledR}$ PCR System 9700 with Dual 384-Well Sample Block Module, and assays were performed on a 384-well plate on the Sequenom MassARRAY platform. We found that elevated breast cancer risk was associated with those who had a family history of breast cancer and history of breast disease, and those who were over 25 years old at first full-term pregnancy. We found that decreased risk of breast cancer was associated with those who had a history of fullterm pregnancies. Compared with the ERCC1 rs11615 T/T genotype, a
\end{abstract}


significantly higher risk of breast cancer was found in the $\mathrm{C} / \mathrm{C}$ genotype in codominant and dominant models after adjusting for potential risk factors. Similarly, we found that ERCC1 rs3212986 C/C genotype was associated with an increased risk of breast cancer in codominant, dominant and recessive models. Our study indicated that the ERCC1 rs11615 and rs2298881 polymorphisms are associated with breast cancer in a Chinese population. Further studies with large sample size are greatly needed to elucidate the SNPs of ERCC1 and XPF genes in the development of breast cancer.

Key words: Excision repair cross-complimentary group 1; Susceptibility; Xeroderma pigmentosum complementation group F; Breast cancer; Polymorphisms

\section{INTRODUCTION}

Breast cancer is one of the most frequently diagnosed cancers in women worldwide. In 2008, it was estimated that 1.38 million new cancer cases were diagnosed, and accounted for $25 \%$ of all cancers (IARC, 2008). It is reported that the etiology of breast cancer is complicated, and a complex interplay of genetics, environmental exposures, hormones, and behaviors may contribute to breast carcinogenesis during specific life phases (Benz, 2008).

DNA repair plays an important role in maintaining the stability and integrity of the human genome. Nucleotide excision repair (NER) is the most versatile pathway that repairs single-stranded DNA by excising damaged sequences and filling the gap with a complementary DNA strand. DNA damage can induce lesions that would distort the double-helix structure, which may be repaired by the NER pathway. The NER pathway is a complex process, which includes almost twenty different genes. Seven xeroderma pigmentosum (XP) complementation groups have been identified, which are rate-limiting in the NER mechanism (Cleaver, 2000). NER is the most versatile pathway, which is involved in bulky adducts, crosslinks, oxidative DNA damage, alkylating damage, and thymidine dimers (De Silva et al., 2000; Friedberg, 2001; Wood et al., 2001). The excision repair cross-complimentary group 1 (ERCC1) gene encodes a subunit of the NER complex required for the incision step of NER, and this protein forms a heterodimer with the XP complementation group F (XPF) endonuclease to catalyze the 5'-incision during the process of excising the DNA lesion (Wang et al., 2011). It is reported that the ERCC1 protein is critical for NER, and that variations in ERCC1 are more likely to influence the genomic stability that plays a role in carcinogenesis (van Duin et al., 1986; Wood, 1997). Three common ERCC1 variants, rs11615, rs321986 and rs321961, have been reported to be associated with cancer risk, such as lung cancer, colorectal cancer, glioma, and head and neck cancers (Zhang et al., 2012b). However, only four studies have reported an association between variations of ERCC1 and breast cancer risk, including one study of 1053 breast cancer cases in the USA, one of 872 cases in Korea, and one of 426 cases in Iran (Lee et al., 2005; Crew et al., 2007; Mojgan et al., 2012). For the association between XPF polymorphisms and cancer risk, one meta-analysis indicated that there was no significant association between polymorphisms in XPF and breast cancer risk (Ding et al., 2011).

To further investigate the association of polymorphisms in ERCC1 and XPF with risk of breast cancer, we conducted a case-control study by genotyping seven potentially func- 
tional SNPs, three in ERCC1 and four in XPF, in a Chinese population of 417 breast cancer cases and 417 cancer-free controls.

\section{MATERIAL AND METHODS}

The subjects were recruited from a case-control study conducted in the First Affiliated Hospital of Zhengzhou University. This study included 443 primary breast cancer patients who were histopathologically confirmed, and 417 cases agreed to participate in our study with a participation of $94.1 \%$. A total of 417 controls were selected from the same hospital during the same time period. Controls were cancer-free Han Chinese who had a health examination at the First Affiliated Hospital of Zhengzhou University. Controls were matched with cases by age ( \pm 5 years) and gender. Blood samples were obtained from all breast cancer patients and controls. All patients signed a written informed consent form for donating their blood sample for our study. Our study was approved by the Institutional Review Board of the the First Affiliated Hospital of Zhengzhou University.

Genomic DNA was extracted from the buffy coat fraction of the blood sample with the Qiagen Blood DNA Mini kit (Qiagen Inc., Valencia, CA, USA) according to manufacturer instructions. DNA purity and concentration were determined by measuring absorbance at 260 and $280 \mathrm{~nm}$ with a UV spectrophotometer (NanoDrop Technologies, Inc., Wilmington, DE, USA). The potentially functional SNPs were selected from the Database of Single Nucleotide Polymorphisms (SNPs) of NCBI (http://www.ncbi.nlm.nih.gov/) and SNPinfo (http://snpinfo. niehs.nih.gov/) with the following criteria: 1) the minor allele frequency $\geq 5 \%$ of the Chinese population; 2) influencing the microRNA binding site activity. Finally, three SNPs in ERCC1 and four SNPs in XPF met the criteria and were selected. For the genotyping assays, Taqman Universal PCR was performed with $5 \mathrm{ng}$ genomic DNA in a reaction volume of $5 \mu \mathrm{L}$. All SNPs were genotyped by using Taqman Universal PCR in a GeneAmp ${ }^{\circledR}$ PCR System 9700 with Dual 384-Well Sample Block Module (Applied Biosystems, Carlsbad, CA, USA), and assays were performed on a 384-well plate on the Sequenom MassARRAY platform (Sequenom, San Diego, CA, USA). The polymorphisms of the seven SNPs were determined by matrix-assisted laser desorption/ionization time of flight mass spectrometry (MALDI-TOF-MS) (Figure 1). Primers for polymerase chain reaction amplification and single base extension assays were designed by the Sequenom Assay Design 3.1 software (Sequenom) according to manufacturer instructions. For quality control, genotyping was repeated for a random sample of $5 \%$ of cases and controls, and the results were $100 \%$ concordant.

\section{Statistical analysis}

The SAS software (version 9.1; SAS Institute, Cary, NC, USA) was used for statistical analyses. Continuous variables are reported as means $\pm \mathrm{SD}$, while categorical variables were shown as frequencies and percentages. Differences in the demographic and clinical characteristics as well as frequencies of the alleles and genotypes between cases and controls were compared by using the $\chi^{2}$ test or the Fisher exact test. The Hardy-Weinberg equilibrium (HWE) of genotype distributions in the control was tested by a goodness-of-fit $\chi^{2}$ test. Conditional multivariate logistic regression models were applied to calculate crude and adjusted odds ratios (ORs) and 95\% confidence intervals (CIs), respectively. Associations between the genotypes 
and risk of breast cancer among subgroups were adjusted by potential risk factors, such as age, family history of breast cancer, history of breast disease, menopausal status, smoking history, age at first full-term pregnancy, and number of full-term pregnancies. All comparisons were two-sided, and $\mathrm{P}<0.05$ was regarded as statistically significant.

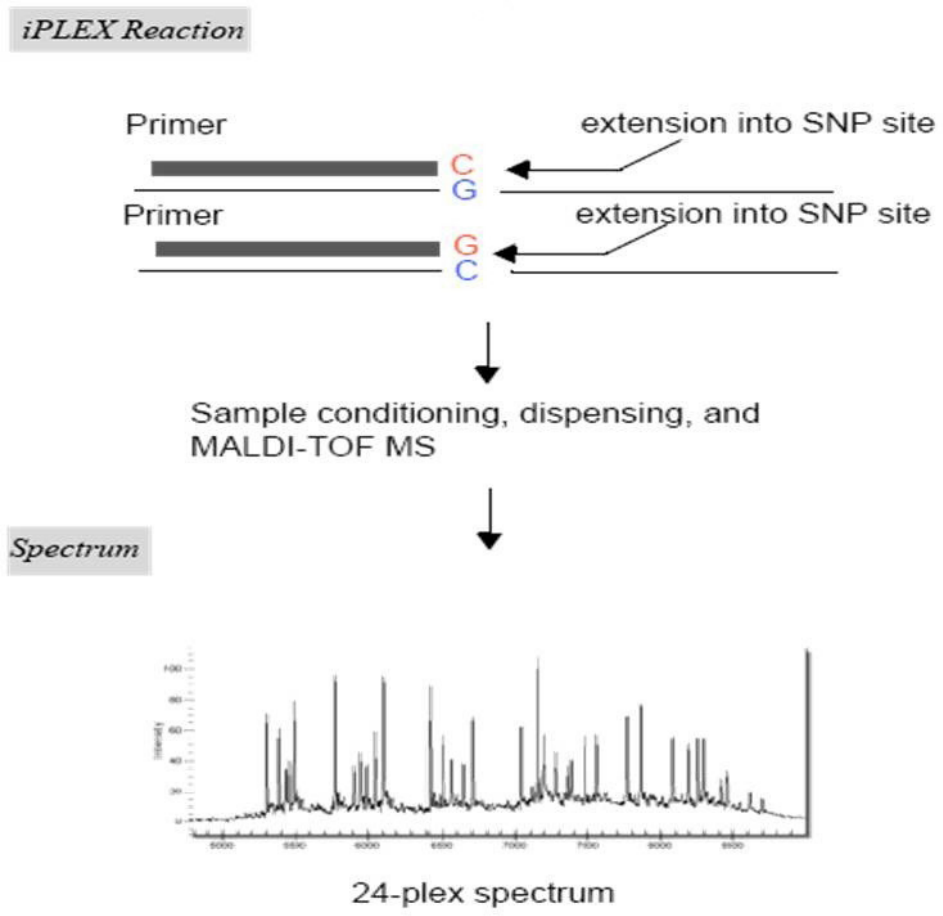

Figure 1. Detection of SNP polymorphisms by MALDI-TOF-MS.

\section{RESULTS}

Demographic characteristics of the selected population are summarized in Table 1. Elevated breast cancer risk was associated with those who had family history of breast cancer $(\mathrm{OR}=2.38 ; 95 \% \mathrm{CI}=1.24-4.78)$ compared with those without such family history, those who had history of breast disease $(\mathrm{OR}=1.44 ; 95 \% \mathrm{CI}=1.05-1.97)$ compared with those without history of breast disease and those who were over 25 years old at first full-term pregnancy compared with those under 25 years old. However, we found that reduced risk of breast cancer was associated with those who had a history of full-term pregnancies compared with those who had no full-term pregnancy.

The distributions of seven SNPs of XPF are shown in Table 2. The genotype distributions of the seven SNPs, rs11615, rs3212986, rs2298881, rs1800067, rs1799797, rs2276465, and rs2276466, did not divert significantly from HWE in controls ( $P>0.05)$. The genotype frequencies of ERCC1 rs11615 and rs3212986 showed a significant difference between cases and controls $(\mathrm{P}<0.05)$. However, we did not find a significant differ- 
ence in the genotype frequencies of ERCC1 rs2298881 and XPF rs1800067, rs1799797, rs2276465, and rs2276466.

Table 1. Clinical and demographic characteristics of breast cancer patients and controls.

\begin{tabular}{|c|c|c|c|c|c|c|}
\hline Variables & Cases & $\%$ & Controls & $\%$ & OR $(95 \% \mathrm{CI})$ & $P$ value \\
\hline Age [years $($ mean $\pm \mathrm{SD})]$ & $47.5 \pm 5.4$ & & $49.7 \pm 7.1$ & & & \\
\hline \multicolumn{7}{|l|}{ Family history of breast cancer } \\
\hline No & 383 & 91.8 & 402 & 96.3 & 1 & \\
\hline Yes & 34 & 8.2 & 15 & 3.7 & $2.38(1.24-4.78)$ & $<0.05$ \\
\hline \multicolumn{7}{|l|}{ History of breast disease } \\
\hline No & 281 & 67.4 & 312 & 74.8 & 1 & \\
\hline Yes & 136 & 32.6 & 105 & 25.2 & $1.44(1.05-1.97)$ & $<0.05$ \\
\hline \multicolumn{7}{|l|}{ Age at menarche (years) } \\
\hline$<12$ & 219 & 52.4 & 197 & 47.3 & 1 & \\
\hline $12-15$ & 139 & 33.3 & 153 & 36.7 & $0.82(0.60-1.12)$ & 0.19 \\
\hline$>15$ & 60 & 14.3 & 67 & 16 & $0.81(0.53-1.22)$ & 0.29 \\
\hline \multicolumn{7}{|l|}{ Menopausal status } \\
\hline Pre- & 131 & 31.4 & 111 & 26.5 & 1 & \\
\hline Post- & 286 & 68.6 & 306 & 73.5 & $0.79(0.58-1.08)$ & 0.34 \\
\hline \multicolumn{7}{|l|}{ Smoking history } \\
\hline Never & 329 & 78.8 & 365 & 87.6 & 1 & \\
\hline Ever & 88 & 21.2 & 52 & 12.4 & $1.87(1.27-2.79)$ & $<0.05$ \\
\hline \multicolumn{7}{|l|}{ BMI $\left(\mathrm{kg} / \mathrm{m}^{2}\right)$} \\
\hline$<19$ & 68 & 16.4 & 77 & 18.4 & 1 & \\
\hline $19-$ & 219 & 52.4 & 223 & 53.5 & $1.11(0.75-1.64)$ & 0.6 \\
\hline $24-$ & 130 & 31.2 & 117 & 28.1 & $1.29(0.82-1.94)$ & 0.27 \\
\hline \multicolumn{7}{|l|}{ Age at first full-term pregnancy } \\
\hline$<25$ & 181 & 43.5 & 228 & 54.6 & 1 & \\
\hline $25-$ & 121 & 29.1 & 103 & 24.7 & $1.48(1.05-2.08)$ & $<0.05$ \\
\hline$\geq 30$ & 114 & 27.4 & 86 & 20.7 & $1.67(1.17-2.38)$ & $<0.05$ \\
\hline \multicolumn{7}{|l|}{ No. of full-term pregnancies } \\
\hline 0 & 33 & 7.8 & 13 & 3.1 & 1 & \\
\hline 1 & 135 & 32.3 & 113 & 27.2 & $0.47(0.22-0.93)$ & $<0.05$ \\
\hline $2+$ & 250 & 59.9 & 291 & 69.7 & $0.34(0.16-0.68)$ & $<0.05$ \\
\hline
\end{tabular}

Table 2. Distributions of ERCC1 and XPF gene polymorphisms and HWE.

\begin{tabular}{|c|c|c|c|c|c|c|c|c|c|}
\hline \multirow[t]{2}{*}{ Variants } & \multirow[t]{2}{*}{ Major/minor allele } & \multicolumn{3}{|c|}{ Patients } & \multicolumn{3}{|c|}{ Controls } & \multirow[t]{2}{*}{ P value } & \multirow{2}{*}{$\frac{\text { HWE (P value) }}{\text { Control }}$} \\
\hline & & $\mathrm{A} / \mathrm{A}^{1}$ & $\mathrm{~A} / \mathrm{a}^{2}$ & $\mathrm{a} / \mathrm{a}^{3}$ & $\mathrm{~A} / \mathrm{A}$ & $\mathrm{A} / \mathrm{a}$ & $\overline{a / a}$ & & \\
\hline ERCC1 rs11615 & $\mathrm{T} / \mathrm{C}$ & 169 & 155 & 93 & 189 & 147 & 81 & $<0.05$ & 0.66 \\
\hline ERCC1 rs3212986 & $\mathrm{G} / \mathrm{T}$ & 201 & 161 & 55 & 222 & 155 & 40 & $<0.05$ & 0.97 \\
\hline ERCC1 rs2298881 & $\mathrm{A} / \mathrm{C}$ & 272 & 91 & 54 & 281 & 89 & 47 & 0.252 & 0.06 \\
\hline XPF rs1800067 & $\mathrm{A} / \mathrm{G}$ & 306 & 77 & 34 & 309 & 78 & 30 & 0.75 & 0.11 \\
\hline XPF rs1799797 & $\mathrm{C} / \mathrm{T}$ & 267 & 90 & 60 & 274 & 88 & 55 & 0.82 & 0.07 \\
\hline XPF rs2276465 & $\mathrm{A} / \mathrm{G}$ & 238 & 132 & 47 & 243 & 131 & 43 & 0.84 & 0.18 \\
\hline XPF rs2276466 & $\mathrm{C} / \mathrm{T}$ & 261 & 101 & 55 & 268 & 96 & 53 & 0.91 & 0.2 \\
\hline
\end{tabular}

$1=$ wild genotype; 2 = heterozygous variant; 3 = homozygous variant.

The association between the polymorphisms in rs11615, rs3212986, rs2298881, rs 1800067 , rs1799797, rs2276465, and rs2276466 and breast cancer risk was analyzed by conditional multivariate logistic regression analysis (Table 3). Compared with ERCC1 rs11615 $\mathrm{T} / \mathrm{T}$ genotype, a significantly higher risk of breast cancer was found in the $\mathrm{C} / \mathrm{C}$ genotype after adjusting for the potential risk factors of age, family history of breast cancer, history of breast disease, menopausal status, smoking history, age at first full-term pregnancy and number of full-term pregnancies, and the ORs $(95 \% \mathrm{CI})$ in codominant and dominant models were 1.42 
(1.03-2.01) and 1.36 (1.05-1.78), respectively. Similarly, we found that the ERCC1 rs3212986 $\mathrm{C} / \mathrm{C}$ genotype was associated with an increased risk of breast cancer in codominant, dominant, and recessive models, with ORs $(95 \% \mathrm{CI})$ of 1.69 (1.06-2.71), 1.37 (1.03-1.74), and 1.59 (1.04-2.56), respectively.

\begin{tabular}{|c|c|c|c|c|c|c|}
\hline \multirow[t]{2}{*}{ Genes } & \multirow[t]{2}{*}{ Major/minor allele } & \multirow[t]{2}{*}{ Case } & \multirow[t]{2}{*}{ Control } & \multicolumn{3}{|c|}{ OR $(95 \% \mathrm{CI})^{1}$} \\
\hline & & & & Codominant & Dominant & Recessive \\
\hline \multirow[t]{3}{*}{ ERCC1 rs11615 } & TT & 165 & 189 & - & - & - \\
\hline & $\mathrm{TC}$ & 155 & 147 & $1.21(0.87-1.66)$ & $1.36(1.05-1.78)$ & $1.26(0.89-1.78)$ \\
\hline & $\mathrm{CC}$ & 97 & 81 & $1.42(1.03-2.01)$ & - & - \\
\hline \multirow[t]{3}{*}{ ERCC1 rs3212986 } & GG & 197 & 222 & - & - & - \\
\hline & GT & 161 & 155 & $1.17(0.86-1.58)$ & $1.37(1.03-1.74)$ & $1.59(1.04-2.56)$ \\
\hline & TT & 60 & 40 & $1.69(1.06-2.71)$ & - & - \\
\hline \multirow[t]{3}{*}{ ERCC1 rs2298881 } & AA & 272 & 281 & - & - & - \\
\hline & $\mathrm{AC}$ & 91 & 89 & $1.06(0.74-1.50)$ & $1.10(0.82-1.48)$ & $1.17(0.76-1.82)$ \\
\hline & $\mathrm{CC}$ & 54 & 47 & $1.19(0.76-1.86)$ & - & - \\
\hline \multirow[t]{3}{*}{ XPF rs 1800067} & AA & 306 & 309 & - & - & - \\
\hline & $\mathrm{AG}$ & 77 & 78 & $1.0(0.69-1.45)$ & $1.04(0.75-1.43)$ & $1.15(0.67-1.98)$ \\
\hline & GG & 34 & 30 & $1.15(0.66-1.99)$ & - & - \\
\hline \multirow{3}{*}{ XPF rs1799797 } & $\mathrm{CC}$ & 267 & 274 & - & - & - \\
\hline & $\mathrm{CT}$ & 90 & 88 & $1.05(0.74-1.49)$ & $1.08(0.80-1.45)$ & $1.11(0.73-1.67)$ \\
\hline & TT & 60 & 55 & $1.23(0.73-1.71)$ & - & - \\
\hline \multirow[t]{3}{*}{ XPF rs2276465 } & AA & 238 & 243 & - & - & - \\
\hline & $\mathrm{AG}$ & 132 & 131 & $1.03(0.65-1.41)$ & $1.05(0.79-1.40)$ & $1.10(0.70-1.76)$ \\
\hline & GG & 47 & 43 & $1.12(0.69-1.80)$ & - & - \\
\hline \multirow[t]{3}{*}{ XPF rs2276466 } & $\mathrm{CC}$ & 261 & 268 & - & - & - \\
\hline & $\mathrm{CT}$ & 101 & 96 & $1.08(0.77-1.52)$ & $1.08(0.80-1.44)$ & $1.04(0.68-1.60)$ \\
\hline & TT & 55 & 53 & $1.07(0.69-1.65)$ & & \\
\hline
\end{tabular}

${ }^{1}$ Adjusted for age, family history of breast cancer, history of breast disease, menopausal status, smoking history, age at first full-term pregnancy, and number of full-term pregnancies.

\section{DISCUSSION}

In this study, we found that ERCC1 rs11615 and rs3212986 were associated with an increased risk of breast cancer in a Chinese Han population. However, we did not find a significant association between variants of the four XPF SNPs and risk of breast cancer. To the best of our knowledge, this is the first study showing that ERCC1 rs11615 and rs3212986 are likely to be associated with risk of breast cancer, and that polymorphisms in XPF may not play a role in the development of breast cancer risk. Because ERCC1 plays a key function in NER pathway, our findings are biologically plausible.

As far as we know, the identification of novel genetic variants for assessing the early risk of breast cancer is attracting great interest in research on cancer risk worldwide (Li et al., 2013; Palmer et al., 2013). On the basis of genetic information, we could determine the genetic etiology of breast cancer, and the genetic factors could be used for identifying the high-risk individuals and targeting therapy according to the individual's genetic make-up.

ERCC1 is located on chromosome 19q13.32 and consists of 10 exons. It encodes a 297-amino acid protein that is involved in correcting the excision repair deficiency of the NER pathway (van Duin et al., 1986; Reed, 1998). It is reported that ERCC1 plays a key role in the process of excising DNA lesions in the repair of DNA damage on the transcribed 
strand of the actively expressed gene and removing DNA damage from the remaining genome (Constantinou et al., 1999; Kamangar et al., 2009). Variants of ERCC1 can reduce DNA damage repair and genomic NER activities and thus contribute to the development of carcinogenesis (Friedberg, 2003). ERCC1 has been reported to be associated with the risk of various cancers, such as gastric cancer, cervical cancer, ovarian cancer, and glioma (Han et al., 2012; He et al., 2012a,b; Zhang et al., 2012a). However, there are only three studies that explore the association between variants of ERCC1 and breast cancer risk, and the results are inconsistent (Lee et al., 2005; Crew et al., 2007; Mojgan et al., 2012). Lee et al. (2005) reported that the ERCC1 8092AA genotypes and the ERCC1 354T allele were associated with breast cancer risk. However, one study conducted in the USA reported that ERCC1 rs3212986C/A was associated with risk of breast cancer (Crew et al., 2007). Another study conducted in Iran indicated that the ERCC1 rs3212981 AA genotype was associated with risk of breast cancer (Mojgan et al., 2012). Our study showed that ERCC1 rs 11615 CC and rs3212986 AA were associated with 1.42- and 1.69-fold risk of breast cancer in the codominant model, which was in line with reports from Lee et al. (2005). The inconsistency of these results may be due to differences in ethnicities, source of controls, sample size, and by chance.

$\mathrm{XPF}$ is located on chromosome 16p13.12, contains 11 exons and spans approximately $28.2 \mathrm{~kb}$, and its product is a key component involved in the 5'-incision made during NER (Wood et al., 2001). XPF forms a tight complex with ERCC1 to be a structure-specific DNA repair endonuclease, and it plays a role in the 5'-primer incision during the process of DNA excision repair (Tripsianes et al., 2005; Tsodikov et al., 2005). Previous studies have reported that XPF is involved in the NER pathway and is linked to susceptibility to XP, a rare recessive syndrome that includes photosensitivity and malignant tumor development (Zhu et al., 2003). Previous few studies reported the effect of XPF on the risk of breast cancer (Smith et al., 2003; Jorgensen et al., 2007; Romanowicz-Makowska et al., 2007). However, the three studies did not find a significant association between variants of XPF rs180067 and breast cancer, and the three studies did not explore the role of XPF rs1799797, rs2276465 and rs2276466 on the risk of breast cancer. Similarly, we also did not show a significant association between the three SNPs and risk of breast cancer. Further large sample size studies are strongly needed to determine their association.

There are two limitations in our study. First, our study selected controls from one hospital, and the controls may not represent the characteristics from other locations. This may be a selection bias since the controls were not a random sample of the general population and may not fully represent the underlying base population. Second, breast cancer is a disease induced by multiple genes and environmental factors. There may be other factors involved in the development of breast cancer, and thus, other genetic and environmental factors may be considered in further studies.

In conclusion, as the first study to investigate the association between polymorphisms in ERCC1 and XPF genes and the risk of breast cancer in a Chinese population, it demonstrated that the ERCC1 rs11615 and rs2298881 polymorphisms are associated with breast cancer in a Chinese population. However, our study did not find a statistically significant association between the variants of rs180067, rs1799797, rs2276465, and rs2276466 in XPF gene and risk of breast cancer. Further studies with large sample size are greatly needed to elucidate the SNPs of ERCC1 and XPF genes in the development of breast cancer. 


\title{
ACKNOWLEDGMENTS
}

\author{
University. \\ We are thankful for the help from staffs of the First Affiliated Hospital of Zhengzhou
}

\section{REFERENCES}

Benz CC (2008). Impact of aging on the biology of breast cancer. Crit. Rev. Oncol. Hematol. 66: 65-74.

Cleaver JE (2000). Common pathways for ultraviolet skin carcinogenesis in the repair and replication defective groups of xeroderma pigmentosum. J. Dermatol. Sci. 23: 1-11.

Constantinou A, Gunz D, Evans E, Lalle P, et al. (1999). Conserved residues of human XPG protein important for nuclease activity and function in nucleotide excision repair. J. Biol. Chem. 274: 5637-5648.

Crew KD, Gammon MD, Terry MB, Zhang FF, et al. (2007). Polymorphisms in nucleotide excision repair genes, polycyclic aromatic hydrocarbon-DNA adducts, and breast cancer risk. Cancer Epidemiol. Biomarkers Prev. 16: 2033-2041.

De Silva IU, McHugh PJ, Clingen PH and Hartley JA (2000). Defining the roles of nucleotide excision repair and recombination in the repair of DNA interstrand cross-links in mammalian cells. Mol. Cell. Biol. 20: 7980-7990.

Ding DP, He XF and Zhang Y (2011). Lack of association between XPG Asp1104His and XPF Arg415Gln polymorphism and breast cancer risk: a meta-analysis of case-control studies. Breast Cancer Res. Treat. 129: 203-209.

Friedberg EC (2001). How nucleotide excision repair protects against cancer. Nat. Rev. Cancer 1: 22-33.

Friedberg EC (2003). DNA damage and repair. Nature 421: 436-440.

Han SS, Kim JW, Lee SH, Kim DH, et al. (2012). ERCC1 C19007T polymorphism and the risk and invasiveness of cervical cancer in Korean women. Asia Pac. J. Clin. Oncol. 8: e63-e67.

He J, Qiu LX, Wang MY, Hua RX, et al. (2012a). Polymorphisms in the XPG gene and risk of gastric cancer in Chinese populations. Hum. Genet. 131: 1235-1244.

He SY, Xu L, Niu G, Ke PQ, et al. (2012b). Predictive value of excision repair cross-complementing rodent repair deficiency complementation group 1 and ovarian cancer risk. Asian Pac. J. Cancer Prev. 13: 1799-1802.

International Agency for Research on Cancer (2008). Globocan 2008: Stomach Cancer incidence, Mortality and Prevalence Worldwide in 2008. IARC, 2008. Available at [http://globocan.iarc.fr/factsheets/cancers/liver.asp]. Accessed October 1, 2013.

Jorgensen TJ, Visvanathan K, Ruczinski I, Thuita L, et al. (2007). Breast cancer risk is not associated with polymorphic forms of xeroderma pigmentosum genes in a cohort of women from Washington County, Maryland. Breast Cancer Res. Treat. 101: 65-71.

Kamangar F, Chow WH, Abnet CC and Dawsey SM (2009). Environmental causes of esophageal cancer. Gastroenterol. Clin. North Am. 38: 27-57, vii.

Lee KM, Choi JY, Kang C, Kang CP, et al. (2005). Genetic polymorphisms of selected DNA repair genes, estrogen and progesterone receptor status, and breast cancer risk. Clin. Cancer Res. 11: 4620-4626.

Li H, Beeghly-Fadiel A, Wen W, Lu W, et al. (2013). Gene-environment interactions for breast cancer risk among Chinese women: a report from the Shanghai Breast Cancer Genetics Study. Am. J. Epidemiol. 177: 161-170.

Mojgan H, Massoud H and Ahmad E (2012). ERCC1 intron 1 was associated with breast cancer risk. Arch Med. Sci. 8: $655-658$

Palmer JR, Ruiz-Narvaez EA, Rotimi CN, Cupples LA, et al. (2013). Genetic susceptibility loci for subtypes of breast cancer in an African American population. Cancer Epidemiol. Biomarkers Prev. 22: 127-134.

Reed E (1998). Platinum-DNA adduct, nucleotide excision repair and platinum based anti-cancer chemotherapy. Cancer Treat. Rev. 24: 331-344.

Romanowicz-Makowska H, Smolarz B and Kulig A (2007). Polymorphisms in XRCC1 and ERCC4/XPF DNA repair genes and associations with breast cancer risk in women. Pol Merkur Lekarski 22: 200-203.

Smith TR, Levine EA, Perrier ND, Miller MS, et al. (2003). DNA-repair genetic polymorphisms and breast cancer risk. Cancer Epidemiol. Biomarkers Prev. 12: 1200-1204.

Tripsianes K, Folkers G, Ab E, Das D, et al. (2005). The structure of the human ERCC1/XPF interaction domains reveals a complementary role for the two proteins in nucleotide excision repair. Structure 13: 1849-1858.

Tsodikov OV, Enzlin JH, Scharer OD and Ellenberger T (2005). Crystal structure and DNA binding functions of ERCC1, a subunit of the DNA structure-specific endonuclease XPF-ERCC1. Proc. Natl. Acad. Sci. U. S. A. 102: 11236-11241.

van Duin M, de Wit J, Odijk H, Westerveld A, et al. (1986). Molecular characterization of the human excision repair gene ERCC-1: cDNA cloning and amino acid homology with the yeast DNA repair gene RAD10. Cell 44: 913-923. 
Wang AT, Sengerova B, Cattell E, Inagawa T, et al. (2011). Human SNM1 A and XPF-ERCC1 collaborate to initiate DNA interstrand cross-link repair. Genes Dev. 25: 1859-1870.

Wood RD (1997). Nucleotide excision repair in mammalian cells. J. Biol. Chem. 272: 23465-23468.

Wood RD, Mitchell M, Sgouros J and Lindahl T (2001). Human DNA repair genes. Science 291: 1284-1289.

Zhang L, Ruan Z, Hong Q, Gong X, et al. (2012a). Single nucleotide polymorphisms in DNA repair genes and risk of cervical cancer: A case-control study. Oncol. Lett. 3: 351-362.

Zhang L, Wang J, Xu L, Zhou J, et al. (2012b). Nucleotide excision repair gene ERCC1 polymorphisms contribute to cancer susceptibility: a meta-analysis. Mutagenesis 27: 67-76.

Zhu XD, Niedernhofer L, Kuster B, Mann M, et al. (2003). ERCC1/XPF removes the 3' overhang from uncapped telomeres and represses formation of telomeric DNA-containing double minute chromosomes. Mol. Cell 12: 1489-1498. 